\title{
Antropologia nos Cursos de Graduação na Área da Saúde: contribuições, relações e diálogos
}

\author{
Camila Sissa Antunes ${ }^{1}$ \\ ${ }^{1}$ Unversidade do Estado de Santa Catarina, Chapecó, SC, Brasil
}

\section{Resumo}

Este artigo reflete sobre o papel da antropologia nos cursos de graduação na área da saúde, resgata brevemente a inserção das temáticas da antropologia nesse campo, bem como analisa a importância e a qualidade das relações estabelecidas no contexto do ensino, indicando pontos de diálogo e mútuas contribuições entre a antropologia e a área da saúde. Procura-se, no decorrer do texto, identificar as principais possibilidades de contribuições teóricas e práticas da antropologia para a formação acadêmica (em nível de graduação) de estudantes da área da saúde. Para esta análise, utilizo tanto construções teóricas como relatos e narrativas de discentes sobre o ensino de antropologia a partir de suas experiências nessa disciplina, coletados a partir de textos escritos em atividades de ensino. Assim, aponto para a influência potencialmente positiva da presença curricular da antropologia nos cursos da área da saúde, reconhecendo a importância da compreensão e da apropriação de conceitos antropológicos pelos estudantes como uma maneira de contribuir em sua formação e em futura prática profissional.

Palavras-chave: Antropologia da Saúde. Antropologia. Saúde. Ensino.

\section{Anthropology in Undergraduate Courses in Health: contributions, relationships and dialogues}

\begin{abstract}
This article shows about the role of anthropology in undergraduate courses in the health area, briefly recovers the insertion of anthropology themes in this field, as well as analyzing the importance and quality of the relationships established in the context of teaching, indicating points of dialogue and mutual contributions between anthropology and the health area. Throughout the text, the goal is to identify possibilities of theoretical and practical contributions of anthropology for students to participate in academic training program (on the undergraduate level) in the field of health. For this analysis, I use both theoretical constructions, reports and narratives about teaching of anthropology from students experiences during this discipline, collected from texts written over teaching activities. Thus, I point to the potential of positive influence of the curricular presence of anthropology in health care courses, recognizing the importance of understanding and appropriating anthropological concepts by students as a way to contribute to their training and future professional practice.
\end{abstract}

Keywords: Anthropology of Health. Anthropology. Health. Teaching. 


\section{Introdução}

A antropologia tem ampliado cada vez mais sua presença curricular em diferentes cursos de graduação e de pós-graduação na área da saúde, oferecendo, a partir do seu corpo de conhecimentos acumulados, embasamento teórico e prático para refletir sobre os processos e as características socioculturais dos fenômenos humanos. Essas experiências de ensino têm se revelado importantes contextos que favorecem as relações e os diálogos, tanto do ponto de vista teórico, resultando em significativas e em importantes produções interdisciplinares, como do ponto de vista prático, impactando positivamente na prática profissional e de pesquisa nessas áreas.

As reflexões que apresento a seguir partem das minhas próprias experiências na docência em cursos de graduação desde 2010 e, mais especificamente, em meu trabalho como professora de antropologia em um curso de enfermagem (desde 2019), também representam uma tentativa de sistematizar aquelas que considero as principais contribuições da antropologia para os futuros profissionais dessa área, as quais abordarei neste artigo, a saber: a) compreensão da saúde e da doença como processos resultantes de múltiplas influências, reconhecendo o papel central do conceito de cultura nessa configuração; b) apreensão das relações de alteridade e da importância do exercício da relatividade cultural; e c) reconhecimento e desconstrução dos preconceitos (etnocentrismo) e da biologicização das práticas em saúde.

Compreendo a docência como uma prática de alteridade e uma experiência dialógica, levada à sua radicalidade quando se trata da conexão entre sujeitos pertencentes a áreas de conhecimento não adjacentes, como o caso das ciências sociais e das ciências da saúde. Apesar de contemporaneamente identificarmos um diálogo cada vez mais próximo entre essas áreas, deve-se reconhecer que a saúde não foi um tema central tratado pelos autores clássicos nas ciências sociais. Segundo Nunes (2006), no âmbito da origem das ciências sociais em saúde, há certa unanimidade em considerar o início da estruturação desse campo específico a partir da Segunda Guerra Mundial.

As dimensões sociais passaram a ser incorporadas nas reflexões sobre saúde a partir dos anos de 1970 no Brasil. Em período anterior, nos Estados Unidos, ainda nos anos de 1950 se desenvolve a antropologia médica, que, em conjunto com outras disciplinas das ciências da saúde, como a epidemiologia e a saúde coletiva, procurara articular saúde e sociedade na compreensão da doença de maneira multicausal, não centrada apenas em explicações biológicas. Assim, podemos entender que a principal contribuição das ciências sociais, nesse sentido, está na compreensão do processo saúde-doença com ênfase para suas dimensões sociais e históricas. 
Segundo Nunes (2014), na América Latina, o desenvolvimento das ciências sociais em saúde foi posterior ao norte-americano e canadense e apresentava pesquisas de temas relacionados à medicina, ao corpo, à doença e ao ensino. Em trabalho anterior, Nunes (1985) caracteriza as aproximações das ciências sociais com algumas temáticas, destacando, entre elas, a questão do ensino. Analisando a inserção das ciências sociais na área da saúde, o autor indica como contribuições: questionamentos sobre o modelo biomédico e o seu papel orientador da formação médica e uma crítica muito contundente ao modelo de ensino, que, então centrado no biológico, passa a ser redimensionado e incluir novas disciplinas no currículo, entre elas, a antropologia, que traz uma abordagem integrada conhecida como biopsicossocial (NUNES, 2005).

Raynaut (2006) aponta, nesse sentido, que a interdisciplinaridade entre as ciências sociais e as ciências da saúde passa principalmente pelo questionamento sobre como podemos compreender as pessoas para além de seu corpo biológico, como sujeitos que pensam, imaginam, simbolizam e estão inseridos em redes, estruturas e formas de pensamento coletivas que afetam seus comportamentos. Assim, também, as ciências sociais precisam atentar para o fato de que os sistemas sociais se assentam em realidades biológicas e corporais, que não podem ser desconsideradas.

Desse modo, entendo que, em sala de aula, a inserção da antropologia nos cursos da área da saúde cumpre um papel que está muito além de compartilhar do olhar antropológico sobre o processo de saúde-doença, inclui também pautar as relações no campo prático da saúde, considerando as relações de alteridade e da importância do exercício da relatividade cultural. Na apresentação teórica dos conceitos de cultura, relativismo e etnocentrismo, a antropologia contribui na construção de relações pautadas não apenas no respeito às diferenças, como também na consideração dessas diferenças como significativa para a compreensão dos fenômenos de saúde e doença.

\section{Ensino de Antropologia como um Campo de Diálogos}

Procuramos argumentar que a antropologia pode contribuir em muitos sentidos por meio dos diálogos teóricos que estabelece em diferentes cursos da área da saúde, pois possibilita ampliar o quadro analítico e perceptivo dos estudantes, e, como afirma Luz (2011), as ciências sociais e humanas têm provocado mudanças da práxis no campo das profissões de saúde, no agir cotidiano, inserindo novas discussões teóricas e metodológicas. Segundo a autora, essa mudança se apresenta, por exemplo, a partir da incorporação dos instrumentos conceituais das ciências sociais em políticas de saúde "[...] que levam em consideração a participação, como atores, de pacientes e de coletivos de usuários, ao incorporar categorias das ciências humanas, como as de sujeito, sofrimento e cuidado, na atenção à saúde de pacientes" (LUZ, 201 1, p. 27). Além disso, as ciências sociais oferecem importantes aportes metodológicos, como a etnografia, ampliando as possibilidades da interpretação dos fenômenos em saúde.

Assim, reconhecendo que historicamente as relações entre as áreas da saúde e as sociais se concretizam tanto no campo da pesquisa como do ensino, será neste último que centrarei meu olhar e análise. Assim, o foco são experiências de ensino em que atuei 
como docente, destacando as problemáticas enfrentadas, as experiências pedagógicas, e, mais diretamente, analisarei alguns trabalhos escritos realizados por estudantes da disciplina de Antropologia da Saúde I.

Clarice Cohn (2011), ao analisar o ensino de antropologia da saúde, sugere um programa de aprendizagem que contemple tanto uma apresentação teórica introdutória como também a utilização de pesquisas antropológicas na área da saúde. Assim, a autora e professora propõe que se apresentem aos estudantes "[...] conceitos-chave da antropologia [...] definidos e problematizados - de modo a instrumentalizar os estudantes a utilizá-los e [...] ir além de essencializações" (COHN, 2011, p. 44). Cohn (2011) reitera durante seu texto a importância de que a antropologia ofereça aos profissionais em formação a compreensão da diferença cultural e da alteridade e de como respeitá-las em sua prática profissional.

Cabe apontar que um dos desafios do ensino de antropologia nos cursos da área da saúde diz respeito ao dilema da prevalência e da ênfase do pensamento científico e racional biomédico da formação nessa área, e a consequente crença na ciência, na biomedicina e na tecnologia como principais, se não exclusivos, meios de compreensão dos processos de saúde-doença, o que pode, como consequência, dificultar a compreensão de outros modos de pensamento e sistemas de explicação da saúde e da doença, como aqueles compartilhados entre povos tradicionais ou pela medicina adjetivada como popular.

Nesse sentido, as discussões de Bruno Latour (2000; 2004) contribuem sobre as relações entre a ciência e a modernidade, demonstrando como a antropologia tem problematizado a construção da verdade e do conhecimento científico, questionando, desse modo, a posição privilegiada de verdade única e absoluta em que se coloca a biomedicina:

\begin{abstract}
Por mais vastos que sejam os laboratórios, por mais que os pesquisadores sejam ligados aos industriais, por mais numerosos que sejam os técnicos, por mais ativos que sejam os instrumentos para transformar os dados, por mais construtivas que sejam as teorias, por mais artificiais que sejam os modelos, nada adianta, vamos declarar sem cerimônia, que a Ciência não pode sobreviver senão com condição de distinguir absolutamente, e não relativamente, as coisas "tal como elas são", da "representação que os humanos fazem delas". (LATOUR, 2004, p. 29)
\end{abstract}

É nesse sentido que muitos autores vêm problematizando sobre a hierarquia do conhecimento científico em detrimento de outros conhecimentos. Amadigi et al. (2009) analisam como o suporte teórico da antropologia pode auxiliar na compreensão das práticas de saúde em diferentes contextos e apontam que o diálogo entre os atores envolvidos no cuidado pode permitir uma percepção para além da explicação biomédica, incluindo o significado do adoecer relacionado às experiências e às vivências de cada um dos atores sociais envolvidos no processo saúde-doença.

Ao comentar sobre como essas dimensões não são consideradas nas relações de cuidado, os autores indicam que uma das causas advém da própria formação acadêmica e profissional, pautada prioritariamente no modelo biomédico, modelo este que é muito importante, porém: 
[...] também apresenta limites, em especial na esfera da subjetividade humana, como a compreensão particular da doença e a vivência do processo de adoecimento e sofrimento. Esse processo é bastante complexo e envolve várias dimensões, como a psicológica, a social, a cultural ou a transcendental. Assim, compreender o processo de adoecer, nos moldes do modelo biomédico, é apenas um dentre tantos outros modos de explicar o adoecer, o tratar, o curar e o cuidar, enfatizando-se que ele não contempla a integralidade do ser humano. (AMADIGI et al., 2009)

Com a intenção de problematizar a naturalização do campo médico, que, na maioria das vezes, tanto nas práticas quanto nas pesquisas dentro do sistema de saúde no Ocidente moderno, é considerado uma verdade universal e absoluta, Langdon e Wiik (2010) argumentam a favor da relativização cultural desses conhecimentos, evitando, dessa forma, práticas e análises etnocêntricas quando do encontro entre diferentes concepções de saúde e doença. Assim, eles ressaltam que:

Os sistemas de atenção à saúde são sistemas culturais, consonantes com os grupos e realidades sociais, políticas e econômicas que os produzem e replicam. Dessa forma, para fins teóricos e analíticos, o sistema de atenção à saúde biomédico deve ser considerado como um sistema cultural, tal qual qualquer outro sistema etnomédico. (LANGDON; WIIK, 2010, tela 180)

Nesse sentido, fica como tarefa do(a) docente de antropologia facilitar esse diálogo e a compreensão, sabendo da dificuldade de, em poucas horas-aula, se comparadas ao tempo de formação pautado nesse primeiro paradigma, desconstruir o etnocentrismo biocientífico (LANGDON; WIIK, 2010) diante de outras explicações do mundo que devem ser consideradas igualmente válidas e pertinentes.

Portanto, o caminho para a antropologia nesse campo é de diálogo contínuo com outras áreas do conhecimento, permitindo trocas e assimilações que beneficiem ambas as áreas, e com tanto os estudantes como os docentes, por meio de uma abertura efetiva para o entendimento de outros modos de compreensão da realidade. Pode contribuir nesse sentido as reflexões de Bell Hooks (2013) sobre a "comunidade pedagógica" que seria construída a partir da partilha de experiências pessoais em sala de aula, de um modo não essencialista, e que teria como resultado o engajamento dos estudantes nas discussões, pois eles sentiriam que os conteúdos discutidos estão vinculados e respondem a inquietações de suas próprias vivências e experiências. A autora aponta também para a importância de transformação da estrutura pedagógica tanto do ensino como do currículo para que efetivamente seja possível o princípio de uma pedagogia engajada, ou seja, não apenas o conteúdo precisa ser emancipado, mas também a prática de ensino. Além disso, para que o ensino das ciências sociais na área da saúde contribua efetivamente, é fundamental que se estabeleçam trocas para além da sala de aula, incluindo o diálogo com os outros componentes que compõem o currículo e a formação discente.

Ao apresentar os desafios para a docência de antropologia em outros cursos que não das ciências sociais, Sartori (2012) aponta, entre eles, a necessidade da busca de efetivo diálogo com os cursos em que a disciplina é ofertada, assim a disciplina não ficaria isolada como apenas mais um aporte teórico, mas poderia efetivamente cumprir sua função curricular e encantar os estudantes com suas possibilidades analíticas. 
Por caminho semelhante, Santos (2018), ao discutir possibilidades curriculares para o ensino de sociologia nos cursos de enfermagem, aponta para o papel importante da multidisciplinaridade, que, em sua compreensão “[...] contribui para que a sociologia também possa ser recepcionada na compreensão do processo saúde/doença, no qual fatores sociais e culturais têm papel extremamente relevante". No mesmo sentido, ao analisar a trajetória da construção teórica da sociologia da saúde, Nunes (2014, p. 1.016) aponta para a importância da interdisciplinaridade nessa elaboração, concluindo que: “[...] a construção teórica é convergente e se realiza a partir de encontros interdisciplinares [...] Sem dúvida, a diversidade temática da saúde é um campo fértil para essa construção".

Assim, pode-se compreender que o ensino de antropologia na área da saúde se torna mais efetivo se combinado com práticas de interdisciplinaridade que permitam relações teóricas e práticas entre as áreas, como uma forma de concretizar o debate analítico desse campo provocado pelas discussões teóricas realizadas em sala de aula.

Como aponta Raynaut (2006, p. 151), essa abordagem pode se pautar em uma interdisciplinaridade consciente:

[...] da relatividade e dos limites de cada campo disciplinar; sobre uma boa informação a respeito do que outras disciplinas podem trazer na construção de um conhecimento mais amplo da realidade; sobre a vontade e a capacidade de fazer trocas, além das fronteiras disciplinares.

Colocadas em relação de complementariedade e não de antagonismo, as áreas das ciências sociais e da saúde podem promover uma formação humana e profissional mais coerente com as demandas do mundo social, cada vez mais plural, dinâmico e fluido.

\section{Contribuições da Antropologia para a Formação na Área da Saúde}

A seguir procuramos sintetizar como a antropologia pode contribuir na formação profissional no campo da saúde, destacando alguns conceitos com os quais os estudantes podem assimilar a perspectiva antropológica e, ao mesmo tempo, relacionar com o próprio campo da sua prática e formação profissional. O primeiro seria o conceito de cultura e a consequente compreensão da saúde e da doença como processos socioculturais, assim como as noções de alteridade, de relativismo cultural e de etnocentrismo, que contribuem para reconhecer e desconstruir os preconceitos e a biologicização das práticas em saúde.

Selecionei para análise neste artigo, minha experiência com a disciplina de Antropologia para a Saúde I, ofertada no curso de graduação em enfermagem, na primeira fase. Optei por esse recorte por oportunizar uma reflexão sobre a relação que se estabelece com estudantes que, muito provavelmente, não tiveram contato com a antropologia anteriormente, o que pode fornecer pontos de reflexão sobre a importância dessa disciplina nesses cursos ${ }^{1}$. Assim também, sendo essa uma disciplina oferecida em um momento inicial do curso, tem como objetivo uma apresentação da

Os trechos citados referem-se aos trabalhos finais da disciplina de Antropologia da Saúde I, oferecida no semestre 2019/2, e também a participações no Fórum de discussão da disciplina de Antropologia da Saúde I semestre 2020/1. Essa disciplina possui uma carga horária de 36 h/a. 
ciência antropológica, que será aprofundada em momento posterior com a disciplina de Antropologia da Saúde II. Conforme descrito no plano de ensino, a disciplina dentro da qual foram desenvolvidas as atividades pedagógicas que originaram os textos que serão analisados a seguir, atem como ementa: "Antropologia da saúde. Estudos etnográficos" e o objetivo geral da disciplina:

Fornecer elementos conceituais e básicos da antropologia da saúde, desenvolvendo no estudante a capacidade analítica para o conhecimento da sociedade contemporânea e da dimensão simbólica do comportamento humano, enfatizando os processos de saúde e doença, considerando aspectos relevantes da relação existente entre cultura, indivíduo e sociedade, a fim de tornar a problemática antropológica um instrumento na prática profissional em enfermagem. (ANTUNES, 2020, p. 1)

Segundo Gusmão (2009), os princípios antropológicos centrais citados e analisados nos grupos de trabalho da Associação Brasileira de Antropologia (ABA) são as questões da relativização e da alteridade. Temas esses que expressariam uma contribuição da antropologia na formação crítica: “[...] pensar a antropologia como parte de uma atitude humanista singular e própria, cujo conhecimento permitiria a emancipação humana e o resgate da cultura de modo crítico e engajado" (GUSMÃO, 2009, p. 39). Estariam, assim, nessas problematizações fundamentais do pensamento antropológico, possibilidades de abertura de horizontes aos estudantes que acessam, por meio da antropologia, essas ferramentas conceituais. Tais ferramentas, dependendo de uma abordagem pedagógica que as relacione com a prática profissional, podem se transformar em instrumentos de mudança das percepções, influenciando, potencialmente, o restante de sua formação acadêmica, assim como sua futura prática profissional.

Na maneira com que concebo as práticas de ensino, a noção de diálogo se torna central, como uma prática que direciona o olhar teórico-metodológico no tratamento e na consideração dos discursos, textos e atividades dos estudantes no contexto de ensino, da mesma forma que fazemos com os interlocutores em campo e nos textos que escrevemos. Essa visão se alinha com o que indica Hooks (2013, p. 200): “No que se refere às práticas pedagógicas, temos que intervir para alterar a estrutura pedagógica existente e ensinar os alunos a escutar, a ouvir uns aos outros". Nesse sentido, a decisão por considerar neste trabalho trechos de textos das próprias estudantes se alinha com essa perspectiva dialógica que permite uma aproximação com as perspectivas do outro e reflete as maneiras pelas quais foram conduzidas as práticas pedagógicas em sala de aula, ou seja, na perspectiva de diálogo horizontal que se materializa na própria consideração dessas vozes discentes neste texto.

Nesse sentido, e na maneira encontrada para relatar as possíveis contribuições da antropologia para estudantes da área da saúde, gostaria de compartilhar trechos de textos coletados em atividades da disciplina, que resultam dos diálogos estabelecidos em sala, com os textos e outros materiais pedagógicos. Esses textos apresentam os tópicos que identifiquei como as principais contribuições que a antropologia pode oferecer na formação acadêmica nas áreas da saúde. Apresentar e discutir os relatos é também uma forma de reconhecer as vozes discentes como aquelas que efetivamente importam quando o objetivo é analisar as contribuições da ciência antropológica para sua formação. 
Os textos das estudantes são apresentados como coadjuvantes na escrita do texto a partir da minha percepção do quão pertinentes são esses relatos.

\subsection{Conceitos Básicos no Ensino de Antropologia}

Os conceitos de cultura, alteridade e relativismo nos permitem ampliar a base de compreensão dos fenômenos humanos, incluindo para além do biológico os aspectos socioculturais, especialmente para compreender como as sociedades lidam com a corporalidade, a doença, a saúde, a busca pela cura, com os sistemas de cuidado, entre outros. A seguir apresento os conceitos básicos que podem ser discutidos em cursos de graduação da área da saúde como forma de apresentar essa dimensão simbólica.

O passo inicial para a compreensão antropológica em sala de aula pode ser feito por meio do conceito de cultura, que foi desenvolvido com certas particularidades por todas as escolas antropológicas e sempre foi o conceito em torno do qual se construíram, ao invés de consensos, antagonismos e diferentes abordagens teóricas. Sem desconsiderar esse debate, o ensino de antropologia para os cursos de outras áreas geralmente não é capaz de problematizar apropriadamente essas questões, uma vez que apresenta uma visão introdutória ao conceito de cultura.

Para essa apresentação do conceito de cultura, um dos textos classicamente usados é o de Roque Laraia (2009) "Cultura: um conceito antropológico". Nesse texto são apontadas algumas características da noção de cultura e como ela opera. A cultura é vista como um elemento adquirido socialmente que transforma a visão de mundo das pessoas, cuja participação no sistema é sempre parcial. O autor destaca que cada cultura tem sua lógica própria, devendo a compreensão dos hábitos e as características culturais serem consideradas no contexto ao qual pertencem. Para discussão na área da saúde, há um capítulo especialmente interessante, intitulado "A cultura interfere no plano biológico". Nele são apresentados exemplos etnográficos da influência dos padrões culturais sobre o campo biológico, demonstrando-se que tanto os processos de adoecimento como os de cura dependem em grande medida dos repertórios culturais acionados pelos sujeitos participantes de culturas específicas, que compartilham, dessa forma, determinados significados sobre o que são as doenças e como tratá-las.

As perspectivas apresentadas nesse texto permitem aos estudantes uma primeira aproximação com a teoria antropológica e já cria uma ampliação do olhar para os fenômenos da saúde e da doença, que conseguem reconhecer na cultura, mesmo nas leituras iniciais, uma importante chave de compreensão, como podemos perceber na narrativa a seguir:

A cultura é uma categoria que pode nos ajudar a compreender melhor o mundo e a sua diversidade. Muitas vezes o conceito de cultura é a tribuído e de certa forma confundido com a inteligência de cada indivíduo, como se fosse uma prova social para o grau de conhecimento. No âmbito social na verdade a cultura é usada para classificar grupos sociais, uma palavra para a diversidade. A palavra cultura, ocupa um importante lugar no conceito de cada pessoa, 
o desenvolvimento da personalidade de cada um está conectado com a sua cultura, [que] se torna a maneira de viver de um grupo ou pessoa. (C. R., estudante de Enfermagem) ${ }^{2}$

A perspectiva adotada por Laraia (2009) se aproxima da antropologia simbólica, que recebeu inspiração da visão de cultura inaugurada por Franz Boas no contexto da antropologia norte-americana: "A concepção boasiana de cultura tem como fundamento um relativismo de fundo metodológico, baseado no reconhecimento de que cada ser humano vê o mundo sob a perspectiva da cultura em que cresceu" (CASTRO, 2004, p. 18). Em continuidade a esse pensamento, Clifford Geertz (1989) desenvolveu em sua antropologia interpretativa a analogia entre cultura e texto, estabelecendo os parâmetros de uma descrição densa das ações simbólicas. Para Geertz (1989), a cultura é pública porque o significado o é, o comportamento não é social em si mesmo, mas na exata medida em que ele é inscrito num sistema significativo por meio do qual os sujeitos veem e interpretam esse comportamento.

Nessa visão, a cultura não é concebida como conjunto de comportamentos ou de regras predeterminadas, a cultura está nos significados identificados pelos agentes sociais. Tal postura compreensiva implica considerar que a objetividade das ciências sociais, particularmente na análise de fenômenos culturais, está na subjetividade dos sujeitos. É por essa razão que um comportamento, por exemplo, não deve ser interpretado por ele mesmo, mas no contexto em que o sujeito o está praticando ou interpretando, ou seja, no contexto em que aquele comportamento se torna inteligível. Essa perspectiva é importante para evitar que se caia na armadilha de que "tudo é cultura" e acabar criando uma centralidade explicativa a partir da cultura.

Na antropologia, o conceito de cultura já foi amplamente discutido, ancorando-se em desconstruções e em reconstruções, ainda, assim, permanece sendo considerado, como afirmam Rocha e Tosta (2009), um "conceito totêmico", uma categoria privilegiada no campo da investigação antropológica, um instrumento pelo qual podemos apreender o significado das ações e das representações sociais desenvolvidas pelos sujeitos em suas vidas cotidianas:

Nesse sentido, podem-se apreender culturas, no plural, enquanto sistemas de símbolos e significados construídos social e historicamente, o que equivale dizer que culturas são mecanismos de controle, orientação e classificação das condutas emocionais, intelectuais, corporais, estéticas, econômicas, políticas, religiosas, morais $[\ldots]$ culturas definem padrões de comportamentos e de sensibilidades fornecendo um sistema de significados às ações humanas. (TOSTA, 2011, p. 245)

Desdobramentos do conceito de cultura surgiram após o movimento intelectual que passou a entender a antropologia como crítica cultural, e, conforme destaca Fischer (1980), a antropologia se define como uma tentativa de diálogo e de aprendizado para o antropólogo, bem como para o grupo que o recebe. Desse modo, procurando dinamizar o conceito de cultura, entende-se que há de ir para além da "descrição densa": "[...] somente situando categorias culturais historicamente, analisando as sociologicamente

Todos os relatos citados neste artigo foram escritos em contexto pedagógico da disciplina de Antropologia da Saúde I, ministrada pela autora deste artigo nos semestres de 2019/1 e 2020/1, no curso de Enfermagem, primeiro período, na UDESC/CEO. As estudantes autorizaram a citação do texto e das suas iniciais neste artigo. 
e explicando sua mudança através do tempo, a 'descrição densa' pode ser salva da trivialidade" (FISCHER, 1980, p. 266). Em consonância com esse pensamento, Roy Wagner (2010) aponta que a "cultura", em suma, é um modo de descrever os outros como descreveríamos a nós mesmos: “Um antropólogo experiencia, de um modo ou de outro, seu objeto de estudo; ele o faz através do universo de seus próprios significados para comunicar uma compreensão aos membros de sua própria cultura" (WAGNER, 2010, p. 29).

Segundo Wagner (2010), ao fazer antropologia, não somente o próprio antropólogo entra em diálogo e experiência com os interlocutores de sua pesquisa, como também sua própria cultura é colocada em relação com a cultura "nativa". Desse modo, passa-se da interpretação geertzeana para uma autorreflexão sobre processos de representação e escrita da cultura. A ideia de Wagner, "somos todos antropólogos", quer dizer: eles, os nativos, também são antropólogos. Wagner proclama a condição antropológica do nativo de modo que o exercício antropológico consistiria basicamente em integrar as antropologias nativas de si próprios e a nossa antropologia deles. A partir das leituras de Wagner (2010), podemos dizer que a atividade da antropologia é fundamentalmente a de "inventar" a cultura, ela estuda a diferença pensando que ali há cultura, e objetiva a sua própria "Cultura" contrastando-a com outras culturas.

Assim, vivenciamos uma transformação da cultura, inicialmente como conjunto de padrões, para teia de significados, e agora entendemos a cultura como invenção. Desse modo, passamos a nos interessar muito mais pelas relações e pelos processos engendrados nos contextos culturais. Como sintetizam Langdon e Wiik (2010, tela 176):

Dado o seu caráter dinâmico e às suas características político-ideológicas intrínsecas, a cultura e os elementos que a caracterizam são fontes mediadoras de transformações sociais, altamente politizados, apropriados, alterados e manipulados por grupos sociais ao longo da história das sociedades, segundo diretrizes traçadas pelos atores sociais que fazem seu uso para estabelecer novos padrões socioculturais e modelos societários.

Tanto Roy Wagner (2010) quanto Marilyn Strathern (2006) concedem primazia ontológica à relação. Para esses autores, de fato, a antropologia é um diálogo com outros modos de pensamento. É uma relação entre uma série de outras relações, que se dão especialmente no campo de pesquisa, mas também para além dele. E se tratando de relação, não há possibilidade de que os termos não se transformem com ela. Assim, esses autores nos ajudam a referenciar nossas práticas docentes a partir da própria ideia de construção do conhecimento antropológico. Wagner (2010) considera duas implicações centrais: primeiro, que o antropólogo passa a abrir mão de uma suposta pretensão objetivista absoluta para uma objetividade relativa baseada em sua própria cultura, ou seja, que o antropólogo não transcende seu objeto, mas é parte dele; e segundo, também se assume que todas as culturas se equivalem, o que Wagner chama de "relatividade cultural" (WAGNER, 2010, p. 29).

A antropologia nasceu a partir do encontro com a alteridade e, nessa trajetória, construiu bases reflexivas sobre o fazer etnográfico, desenvolvendo possibilidades analíticas sobre os métodos de pesquisa, sobre o encontro etnográfico, a produção de teorias, etc., problematizando a prática antropológica através da reflexividade. Esse 
diferencial da antropologia será um dos aspectos que a fará, a partir dos anos de 1960, com o surgimento da pós-graduação específica, passar a ser incluída nos currículos de vários cursos de graduação. Como afirma Oliveira (2019, p. 672), "Pensar o lugar da antropologia no mundo é pensar também o lugar de seu ensino, seja na universidade, seja em outros espaços".

Segundo Sartori (2012), a antropologia é demandada nos mais diversos cursos por seu potencial teórico e prático que passa necessariamente pela compreensão do Outro. Essa compreensão considera central as relações de alteridade que estão ligadas ao reconhecimento do Outro em sua diferença numa relação de respeito. É importante lembrar que, quando nos referimos a um Outro, estamos comunicando sobre uma relação nós(eu)-eles(tu) e torna-se fundamental, do ponto de vista da antropologia, buscar compreender as experiências e os significados atribuídos pelo Outro a essas experiências.

\begin{abstract}
A experiência da alteridade (e a elaboração dessa experiência) leva-nos a ver aquilo que nem teríamos conseguido imaginar, dada a nossa dificuldade em fixar nossa atenção no que nos é habitual, familiar, cotidiano, e que consideramos "evidente". Aos poucos, notamos que o menor dos nossos comportamentos (gestos, mímicas, posturas, reações afetivas) não tem realmente nada de "natural". Começamos, então, a nos surpreender com aquilo que diz respeito a nós mesmos, a nos espiar. O conhecimento antropológico da nossa cultura passa inevitavelmente pelo conhecimento das outras culturas; e devemos especialmente reconhecer que somos uma cultura possível entre tantas outras, mas não a única. (LAPLANTINE, 2000, p. 21)
\end{abstract}

Sendo um pressuposto basilar da antropologia, a relatividade da cultura fornece, quando traduzida para o contexto das relações de cuidado, uma base de reconhecimento da parcialidade do conhecimento biomédico, da necessidade de abordagens mais totalizantes das experiências dos indivíduos, incluindo suas próprias experiências, visões de mundo, explicações, sentidos e sentimentos, numa abordagem que englobe muito além do seu corpo biológico e considere também os elementos mentais, emocionais, culturais, etc. na abordagem do processo saúde-doença.

É nesse sentido que se propõe pensar em como a antropologia pode contribuir na prática profissional, sendo possível vislumbrar as possibilidades desse impacto a partir das reflexões desenvolvidas pelas estudantes quando em contato com esses conteúdos e estimuladas a escreverem a esse respeito. Sem romantizar essas questões e sabendo que há muitos desafios a serem superados socialmente, pode-se reconhecer a relevância dessas reflexões por conectar o tema da relatividade no reconhecimento da alteridade nos contextos de cuidado. Trago a seguir alguns relatos retirados de trabalhos acadêmicos que apontam, por exemplo, a conexão desses conceitos com a promoção de políticas de saúde mais eficazes:

Constatamos que é preciso conhecer a diversidade cultural para a formulação de políticas e prestação de serviços, a fim de possibilitar melhor atenção e cuidado no atendimento das demandas da população para a solução dos problemas sociais. É preciso que os serviços de saúde busquem aceitar e aprender com cada cultura, conhecendo as diversas realidades e costumes dos integrantes destes grupos. (D. V., estudante de Enfermagem)

Assim como aponta a importância de reconhecer as relações de alteridade nos processos de compreensão das realidades das populações atendidas nos contextos de 
cuidado, e se coloca no papel profissional, refletindo sobre o lugar dos conceitos discutidos teoricamente de maneira prática (aplicada):

[...] nós futuros profissionais da saúde, precisamos compreender os contextos sociais e culturais em que cada usuário está envolvido, exercitando o ato de reflexão colocado acerca dessa temática, desenvolvendo o olhar do outro para construção de uma percepção sensivel, a fim de superar barreiras culturais e morais, vivenciando diferentes processos de saúde, doença e cura, permitindo uma boa qualidade dos serviços em saúde. (D. V., estudante de Enfermagem)

Nos parece relevante pensar, dentro dos limites que temos para a análise, que as estudantes tenham sido capazes de compreender, ao menos parcialmente a pertinência dos conceitos antropológicos, e que, ao mesmo tempo, apontem para suas aplicações práticas. Não é possível aqui aferir sobre a efetividade ou não desse aprendizado, os relatos nos servem de aporte na demonstração das potencialidades desses conceitos para o reconhecimento e crítica de preconceitos presentes em nosso cotidiano.

Contribuem também, nesse sentido, os conceitos de etnocentrismo e relativismo, que são dois dos conceitos antropológicos que se mostram mais difundidos entre as outras áreas de conhecimento, sendo, ao lado do conceito de cultura, aqueles mais explorados no ensino de antropologia para a área da saúde. Etnocentrismo pode ser definido como:

[...] uma visão do mundo onde o nosso próprio grupo é tomado como centro de tudo e todos os outros são pensados e sentidos através dos nossos valores, nossos modelos, nossas definições do que é a existência. No plano intelectual, pode ser visto como a dificuldade de pensarmos a diferença; no plano afetivo, como sentimentos de estranheza, medo, hostilidade, etc. (ROCHA, 1988, p. 5)

Sendo assim, o etnocentrismo é uma realidade presente em todas as sociedades, condicionado pela história e pelo presente cotidianamente, como distorções que afetam emoções, pensamentos, imagens e representações da diferença (ROCHA, 1988). Isso de tal forma que a antropologia, ao reconhecer essa característica da vida humana, procura estabelecer que para o estudo das outras culturas é preciso considerar cada grupo em suas especificidades, inaugurando a perspectiva que se denomina relativismo cultural, quando o "outro" passa a ser fonte de reflexão, de transformação do próprio protagonista da análise. Essa passagem do etnocentrismo à relativização se tornou o compromisso antropológico na busca pela compreensão da diferença, e a inserção desse debate dentro de outras áreas representa a abertura para a alteridade no campo científico, como afirma Rocha (1988, p. 17):

Toda vez que um campo de conhecimento se abre, se lança de frente para a complexidade, ele também se relativiza. As possibilidades de explicação, por não serem mais de um só tipo, passam a se contrapor, a necessitarem de refinamento maior no seu debate.

No momento em que as ciências da saúde possibilitam esse diálogo com a antropologia, elas apresentam aos estudantes:

[...] conceitos que são conhecidos apenas popularmente, sem entender como surgem e como podem interferir no cotidiano da enfermagem e saúde num coletivo, sendo [...] de suma importância o papel da Antropologia no estudo humano, auxiliando na busca por melhorias e entendimentos no meio social. (M. P. O., estudante de Enfermagem) 
A partir da clareza de como as relações no contexto de cuidado devem ser pautadas na alteridade, o passo seguinte é reconhecer e superar as práticas etnocêntricas no contexto dessas relações, isso é fundamental para que se desnaturalizem certas práticas preconceituosas, inserindo um olhar mais integral sobre os sujeitos em suas características biopsicossociais.

Os comportamentos etnocêntricos desde os primórdios acompanham o desenvolvimento moral do ser humano. No cuidado, os profissionais da saúde como cientistas, tendem a acreditar que o seu conhecimento [científico] é o correto e único, e muitas vezes não levam em consideração a opinião do próprio paciente inserindo-se em uma posição de hierarquia médico/paciente, deixando um grande 'abismo' na relação entre ambos. Tanto o paciente quanto o profissional que o atende deve levar em consideração que, cada um tem suas crenças, costumes e particularidades que devem ser respeitadas no momento do tratamento, pois isso afetará diretamente no processo de cura de cada paciente. (C. K., estudante de Enfermagem)

A não compreensão e o julgamento da crença e cultura do paciente no processo saúde-doença é um exemplo de atitude etnocêntrica ainda muito visto no âmbito da saúde. Devemos sempre enxergar o indivíduo como um todo considerando suas crenças, cultura, valores, hábitos, etc. e nunca enxergando ele apenas num olhar fisiológico ou natural, precisamos estar capacitados para agir e pensar além disso. (M. E. R. C., estudante de Enfermagem)

Os relatos acima apontam para a importância de observar quais atitudes são etnocêntricas nas relações de cuidado e o quanto se pode incorporar um olhar relativista para essas relações, para que não apenas se evitem constrangimentos e preconceitos, mas, a partir do qual, se realize um atendimento muito mais eficiente, humano e respeitoso, como comentam as estudantes:

[...] há muitos julgamentos dos profissionais da saúde pelas culturas e saberes dos pacientes, muitos dizem não sentir tais preconceitos, mas podemos notar o jeito em que tratam ume tratam outro é totalmente diferente, apenas pelo fato da cor, do modo de vestir, etc. (E. C. F., estudante de Enfermagem)

[Daí] a importância da Antropologia no campo da saúde, e da graduação: formar profissionais prontos a atender, sem pré-julgamentos ou de maneira etnocêntrica, visando o bem-estar do paciente, sua melhor compreensão e estar sempre aberto para aprender com o outro. (S. F. S., estudante de Enfermagem)

[...] fortalecendo as relações interpessoais e contribuindo para a prática de saúde mais consciente, a partir da visão de que saúde e doença são construções socioculturais, e não se deve julgar o outro a partir da cultura e visão de mundo própria. A antropologia traz uma visão humanista e ressignificada para o cotidiano dos profissionais da atenção à saúde, compreendendo as peculiaridades de cada indivíduo, analisando o todo, deixando de lado o etnocentrismo. (T. O. F., estudante de Enfermagem)

Sabe-se que apenas o reconhecimento desse etnocentrismo é uma primeira etapa de um processo de transformação e de crítica da própria formação profissional que as estudantes recebem na graduação como um todo, e que, em muitos aspectos, está centrada prioritariamente no conhecimento técnico, figurando as disciplinas das ciências sociais, na maioria das vezes, apenas como exigências normativas e isoladas no currículo, sem receber o devido reconhecimento de sua importância. No entanto, a inserção da antropologia e da sociologia nos cursos da área da saúde, mesmo que ainda realizada de maneira parcial (como no caso da disciplina em questão, que possui apenas dois 
créditos, correspondendo há apenas 36 horas aula), representa um primeiro espaço de debate das acadêmicas com esse conteúdo, com um alcance limitado e pontual, ainda assim, as respostas recebidas nas atividades pedagógicas realizadas e as discussões em sala apontam para a validade e a importância de que esses conteúdos sejam cada vez mais incorporados e ampliados dentro dos cursos de graduação.

\title{
4 O Processo Saúde-Doença
}

Além de reconhecer que são variadas e múltiplas as formas pelas quais os grupos humanos representam, vivenciam e significam as experiências do adoecer e do curar, a antropologia nos permite olhar para o processo de saúde e doença no contexto da interação entre a natureza e a cultura, acessando as significações culturais atribuídas aos infortúnios físicos, suas influências econômicas e sociopolíticas, os engajamentos nos processos terapêuticos e como os sistemas médicos refletem as realidades sociais, entre outros temas relevantes.

Gualda (2009, p. 41), ao sintetizar algumas premissas da antropologia médica, destaca pontos-chave para a compreensão do processo saúde-doença:

\begin{abstract}
A doença e a cura são experiências humanas básicas e melhor compreendidas no complexo das relações entre a biologia e a cultura; A doença é influenciada por comportamentos culturais específicos e condições econômicas e sociopolíticas; O corpo humano e os sintomas são interpretados por meio dos filtros das crenças culturais; Aspectos culturais dos sistemas de cura tem consequências pragmáticas importantes para a aceitabilidade, a eficácia e a melhoria da saúde nas sociedades humanas.
\end{abstract}

Em síntese, é fundamental compreender que a doença representa, além de sinais que interferem no corpo físico, um conjunto de experiências partilhadas intersubjetivamente e pertencentes às redes de significados dos sujeitos que adoecem, daqueles que cuidam, e de todos os sistemas de saúde envolvidos (GUALDA, 2009). Sua compreensão passa pelo processo de reconhecimento dos sintomas, a definição e classificação da doença, os itinerários terapêuticos, os tratamentos, etc. A gestão e os caminhos para a busca pela cura são sempre negociados entre diversos agentes de uma rede extensa e podem envolver diferentes sistemas de saúde, assim, "[...] as questões relativas à saúde e à doença não podem ser analisadas de forma isolada das demais dimensões da vida social, mediadas e permeadas pela cultura que confere sentido a essas experiências" (LANGDON; WIIK, 2010, tela 180).

Portanto, a compreensão do processo saúde-doença passa pelo reconhecimento da parcialidade do conhecimento biomédico e pela importância fundamental do reconhecimento da complexidade de relações e de ressignificações que perpassam as experiências de adoecer e de curar, incluindo múltiplos agentes, instituições e contextos culturais. Sendo esse conceito, na minha perspectiva, uma das mais importantes contribuições da antropologia para a área da saúde, é fundamental que seja discutido, pois permite articulações entre os planos individual e coletivo, entre experiências, ações e negociações de significados, reconhecendo que: 
Diante da visão antropológica o processo saúde-doença vai muito além do que apenas, de fato, a saúde ou doença desse paciente. Diversos aspectos devem ser analisados, o ambiente onde essa pessoa vive, de que forma vive, no que acredita, sua cultura e diversos outros tópicos nesse sentido. (L. S., estudante de Enfermagem)

o processo saúde-doença pode ser entendido como o período de aceitar, entender e reconhecer o que está acontecendo com o indivíduo biologicamente e culturalmente [...] É necessário levar em questão a parte cultural desse processo, entender que a doença causa consequências importantes no grupo social do indivíduo [...] Como lido em um dos textos complementares é nesse processo que se começa a atribuição do significado para a doença, pois a partir do momento que a pessoa adquire a doença, ela começa a atribuir significados individual para ela [...] $e$ também entender como a doença pode ser influenciada pelos comportamentos culturais, as condições econômicas e a relação do indivíduo com a sociedade. (E. M. M., estudante de Enfermagem)

Conceber o processo de saúde-doença na perspectiva antropológica amplia os horizontes para a compreensão das dinâmicas relações que se estabelecem no contexto do cuidado, desde a percepção do adoecer até os itinerários terapêuticos, que incluem uma ampla e complexa rede de socialidades.

Entre as abordagens da antropologia para a compreensão desse processo saúdedoença, está a que considera as narrativas da doença: “O ato de contar história sobre a sua doença é uma tentativa instigada pela doença física, para dar voz à experiência que a medicina não pode descrever. A voz está corporificada em uma pessoa, mas é igualmente social" (FRANK, 1985 apud GUALDA, 2009, p. 46). Nessa perspectiva, a doença é uma forma complexa e dinâmica de relacionamentos, um objeto de síntese, e faz parte de um sistema simbólico, que passa por uma contínua reconfiguração pela pessoa que adoece a partir da sua experiência vivida, das relações com os profissionais, com leituras, informações. Desse modo, “[...] compreende-se a doença na perspectiva dos outros e da própria narrativa, as opiniões vão emergindo no decorrer do processo e nenhuma síntese é completamente finalizada". (GOOD, 1996 apud GUALDA, 2009, p. 47).

o processo saúde-doença de cada um é diferente e único. A antropologia nos faz refletir de como a cultura, as questões socioeconômicas e sociopoliticas influenciam nesse processo. O desenvolvimento de uma doença além de envolver a biologia, engloba as individualidades da pessoa, em como ela vai reagir e proceder com a situação, acontecendo a regressão ou progressão da enfermidade. (V. L., estudante de Enfermagem)

[...] o processo antropológico para a compreensão da saúde-doença procura entender o ser humano e suas diferentes culturas e formas de interpretar o mundo e a condição de cada indivíduo pela busca da cura, a doença e a cura são processos biológicos, mas esses processos para cada indivíduo de certa forma sofre uma interferência da cultura e da condição social, as experiências que a doença proporciona, física, psicológica, toda a sistemática passa pelo indivíduo e pelo seu meio cultural. (C. R., estudante de Enfermagem)

Ressalta-se, nesse sentido, como a experiência do adoecer e a maneira com que se vivencia e se relata essa experiência terão particularidades pautadas na situação de vida e contexto social de cada pessoa.

Retomando o que discutimos anteriormente sobre a necessidade de que se aprofundem os diálogos entre as áreas da saúde e as ciências sociais, podemos partir da discussão crítica da noção de biomedicina, que enquadra o que conhecemos comumente apenas 
por "medicina" como sendo uma das formas possíveis de compreender o processo saúde-doença:

A biomedicina é uma etnomedicina da cultura ocidental; Todas as etnomedicinas são enraizadas em pressupostos culturais, crenças e valores associados às regras de conduta e articulados a um contexto mais amplo; Todos os sistemas manipulam símbolos que evocam as crenças; Todos os sistemas médicos envolvem sistemas de símbolos no processo de cura. (GUALDA, 2009, p. 41)

Sendo a biomedicina o sistema hegemônico no ocidente que efetivamente expressa essa predominância no processo de formação acadêmica, cabe à antropologia da saúde, como componente curricular dos cursos dessa área, contribuir para sua relativização, trazendo aportes críticos às naturalizações inerentes à cultura médica. Nesse sentido, Langdon (2009, p. 324) aponta como a antropologia da saúde entende a biomedicina como um sistema cultural:

\begin{abstract}
A biomedicina como ciência trabalha com universais, no sentido que as doenças são concebidas como unidades universais cujas manifestações são independentes do contexto onde acontecem. Em geral, os pesquisadores da ciência biomédica acreditam que seus métodos positivistas revelam a vida objetivamente e aproxima a que pode ser considerada "verdade", livre de valores, subjetividades e especificidades culturais. A visão que existe um conhecimento único sobre doença e saúde se torna uma barreira para entender as contribuições e implicações do relativismo antropológico. Guiado pelo princípio de relativismo, a Antropologia entende que os saberes e práticas de qualquer sistema médico são construções socioculturais. Dessa forma, nossa própria ciência, como todos os sistemas de conhecimento, emergiu através de processos históricos e socioculturais, e não através da descoberta de leis únicas e universais que regem sobre o mundo real. Nesse sentido, a Antropologia busca não invalidar outros conhecimentos, mas busca relativizálos, reconhecendo que existem outras maneiras de produzir o conhecimento sobre saúde e doença, e não só a da biomedicina. Existem sistemas médicos diversos e todos são construções socioculturais. Todos, também, têm suas limitações em resolver os problemas de saúde.
\end{abstract}

Pelo que me parece, a enfermagem pode ocupar esse papel de tradução entre sistemas, reconhecendo, por meio das discussões sobre culturas, relativismo e alteridade, "[...] como os profissionais também precisam ter um olhar antropológico com os pacientes, para conseguir entendê-los melhor". (E. M. M., estudante de Enfermagem). Assim,

A biomedicina tem um papel importantíssimo na cura de doenças, mas não pode caminhar sozinha. Nós como profissionais da área da saúde devemos ser empáticos e nos colocar no lugar do outro, pois cada ser é diferente, cada um possui a sua cultura e o seu processo de cura também". (V. L., estudante de Enfermagem)

A biomedicina foi criada para identificar os conceitos de doenças, e os sistemas de cuidado. A sua importância se encontra em vários tópicos de estudo, onde a saúde, a doença e a cura em seus diferentes modos são estudados, por isso se vê necessário à sua comunicação com as diferentes práticas de saúde, para que assim exista uma mútua ajuda para identificar o melhor tipo de tratamento para cada indivíduo, tendo o respeito e a compreensão com o paciente e a sua cultura. (C. R. R., estudante de Enfermagem) 
Sem desconsiderar os limites apresentados em um contexto de ensino em que a Antropologia oferece uma pequena contribuição na formação acadêmica dessas estudantes, são importantes as discussões teóricas apresentadas nesta disciplina. Acredito que quando articulados aos contextos cotidianos da área da saúde, tais discussões podem contribuir na desmistificação das práticas e inserir o diálogo e o reconhecimento do Outro como viés da atuação profissional.

Certamente, se durante a formação profissional tivermos bom entendimento de como se molda o processo de saúde e doença poderemos em um futuro profissional próximo nos tornarmos bons enfermeiros, com uma boa e eficaz assistência ao paciente, pois a sociedade está em constante evolução e os conceitos de tempos atrás já não são mais os mesmos que podemos perceber atualmente. Assim, compreender o estudo da sociedade nos deixa intelectualmente atualizados e informados a respeito de todas essas questões. (J. G. L., estudante de Enfermagem)

Portanto, a Antropologia contribui bastante para a formação de profissionais da saúde, pois vai nos ajudar a compreender as práticas de saúde nos diferentes contextos de vida humana. Pois amplia o olhar, permitindo mudanças na relação profissional-usuário, e esse novo olhar pode resultar em cuidados e práticas como escuta atenta, com interesse no paciente e a disponibilidade para juntos buscarem formas singulares para enfrentar a situação vivenciada. Pode se dizer que a Antropologia ultrapassa os limites biomédicos, pois ela reconhece as angústias, os medos, os sofrimentos, as questões fisiológicas e culturais que afetam o ser humano. (L. S. A., estudante de Enfermagem)

Os relatos apresentados neste texto, assim como as discussões teóricas que permearam este artigo, nos permitem vislumbrar as possibilidades da antropologia, por meio das práticas de ensino, oferecer ferramentas teórico-conceituais importantes para uma formação acadêmica que seja crítica e que possa relativizar o próprio campo biomédico, não apenas incluindo outros saberes e explicações do processo saúde-doença, como também compreendendo os limites e como a própria área da saúde está enviesada por uma perspectiva específica da realidade, na construção de verdades parciais, que são consideradas, na maioria dos casos, universais. O exercício de considerar e de analisar a produção dos textos das estudantes elaborados em contexto de ensino e a partir deles pensar as possíveis contribuições da antropologia, me fizeram perceber a importância de algo que motiva minha própria prática docente: a experiência da reciprocidade no contexto de ensino.

Muito me motiva perceber que, em poucas horas de diálogos e de aprendizados, seja possível realizar esses registros reflexivos, porém ciente de que ainda há um longo caminho a ser percorrido. Acredito que nessas trocas, entre a antropologia e a área da saúde, personificadas na docente e nas estudantes em sala de aula, se fazem diálogos muito promissores. Entendo que são experiências como essas que podem amparar debates que nos permitam aprofundar e ampliar os diálogos das ciências sociais com a área da saúde, no contexto do ensino, da pesquisa e da extensão, e que possam nos oferecer possibilidades de novas formas de colaboração entre as duas áreas que tornem as relações de cuidado mais integrais. 


\section{Referências}

AMADIGI, Felipa Rafaela et al. A antropologia como ferramenta para compreender as práticas de saúde nos diferentes contextos da vida humana. REME - Rev. Min. Enferm., [s.l.], v. 13, n. 1, jan.-mar., 2009. Disponível em: http://www.reme.org.br/artigo/detalhes/173. Acesso em: 13 jul. 2021.

ANTUNES, Camila Sissa. Plano de Ensino da disciplina Antropologia da Saúde I: Curso Enfermagem, Universidade do Estado de Santa Catarina, Centro de Educação Superior do Oeste, 2020.

CASTRO, Celso. Apresentação. In: BOAS, Franz. Antropologia cultural. 7. Reimpressão. Tradução Celso Castro. Rio de Janeiro: Zahar, 2004. p. 7-23.

COHN, Clarice. O Ensino de Antropologia da Saúde na Graduação: uma experiência. Saúde Soc., São Paulo, v. 20, n. 1, p. 41-49, 2011.

FISHER, M. Iran: From Religious Dispute to Revolution. Cambridge, Mass: Harvard University Press, 1980.

GEERTZ, Clifford. Uma descrição densa: por uma teoria interpretativa da cultura. In: GEERTZ, Clifford. A interpretação das culturas. Rio de Janeiro: Guanabara, 1989. p. 13-41.

GUALDA, Dulce Maria Rosa. As dimensões e os significados de saúde e doença nas perspectivas médica e popular. In: NAKAMURA, E.; MARTIN, D.; SANTOS, J. F. Q. (org.). Antropologia para enfermagem. Barueri, SP: Manole, 2009. p. 36-55. (Série Enfermagem). GUSMÃO, Neusa Maria Mendes de. Entrelugares: antropologia e educação no Brasil. Educação, Santa Maria, v. 34, n. 1, p. 29-46, jan.-abr., 2009.

HOOKS, Bell. Ensinando a transgredir: a educação como prática da liberdade. São Paulo: Martins Fontes, 2013.

ANGDON, E. J. M. Dialogando sobre o processo saúde/doença com a Antropologia: entrevista com Esther Jean Langdon. [Entrevista concedida a] Sandra Greice Becker, Luciana Martins Rosa, Gisele Cristina Manfrini, Marli Terezinha Stein Backes, Betina H. S. Meirelles, Sílvia Maria Azevedo dos Santos. Rev. Bras. Enferm. [s.l.], v. 62, n. 2, abr., 2009.

LANGDON, E. J.; WIIK, F. B. Antropologia, saúde e doença: uma introdução ao conceito de cultura aplicado às ciências da saúde. Rev. Latino-Am. Enfermagem, [s.l.], v. 18, n. 3, [9 telas], maio-jun., 2010.

LAPLANTINE, F. Aprender Antropologia. São Paulo: Brasiliense, 2000.

LARAIA, Roque de Barros. Cultura: um conceito antropológico. 24. ed. Rio de Janeiro: J. Zahar, 2009.

LATOUR, Bruno. As políticas da Natureza. São Paulo: EDUSC, 2004.

LATOUR, Bruno. Ciência em Ação. São Paulo: Editora da UNESP, 2000.

LUZ, Madel Terezinha. Especificidade das contribuições dos saberes e práticas das ciências sociais e humanas para a saúde. Saúde Soc., [s.l.], v. 20, n. 1, p. 22-31, 2011.

NUNES, Everardo Duarte. As ciências sociais em saúde na América Latina: tendências e perspectivas. Brasília, DF: OPAS, 1985.

NUNES, Everardo Duarte. Ciências Sociais em Saúde: uma reflexão sobre sua história. In: MINAYO, M. C. S.; COIMBRA JR., C. E. A. (org.). Críticas e atuantes: ciências sociais e humanas em saúde na América Latina. Rio de Janeiro: Editora FIOCRUZ, 2005. p. 19-31. [on-line] 
NUNES, Everardo Duarte. A trajetória das Ciências Sociais na área da Saúde em saúde na América Latina: revisão da produção científica. Rev. Saúde Pública, [s.l.], v. 40, n. Especial, 2006.

NUNES, Everardo Duarte. A construção teórica na sociologia da saúde: uma reflexão sobre a sua trajetória. Ciência \& Saúde Coletiva, [s.l.], v. 19, n. 4, p. 1.007-1.018, 2014.

OLIVEIRA, Amurabi. Arthur Ramos e a rotinização da Antropologia através de seu ensino. Civitas, Porto Alegre, v. 19, n. 3, p. 659-674, set.-dez., 2019.

RAYNAUT, C. Interfaces entre a antropologia e a saúde: em busca de novas abordagens conceituais. Rev Gaúcha Enferm., Porto Alegre, RS, v. 27, n. 2, p. 149-65, jun., 2006.

ROCHA, G.; TOSTA, S. P. Antropologia e Educação. Belo Horizonte: Autêntica, 2009.

ROCHA, Everardo P. G. O que é etnocentrismo. São Paulo: Editora Brasiliense, 1988.

SANTOS, Elisângela da Silva. O ensino de sociologia nos cursos de enfermagem: discutindo possibilidades curriculares. Rev. bras. Estud. Pedagog., Brasília, DF, v. 99, n. 253, p. 633-648, set.-dez., 2018.

SARTORI, Ari José. O ensino da antropologia para quem não vai ser antropólogo. Revista Percursos, Florianópolis, v. 13, n. 1, p. 99-119, jan.-jun., 2012.

STRATHERN, Marilyn. O gênero da dádiva: problemas com as mulheres e problemas com a sociedade melanésia. Campinas: Editora Unicamp, 2006.

TOSTA, Sandra Pereira. Antropologia e Educação: interfaces em construção e as culturas na escola. Revista Inter-Legere, [s.l.], Educação e Sociedade, n. 9, p. 234-252, 2011.

WAGNER, Roy. A invenção da cultura. São Paulo: Cosac Naify, 2010.

\section{Camila Sissa Antunes}

Doutora em Antropologia Social pelo PPGAS/UFSC em 2015; mestre em Antropologia Social também pelo PPGAS/UFSC em 2009; bacharel em Ciências Sociais pela Universidade Federal de Santa Catarina em 2007. É pesquisadora vinculada à Rede de Pesquisadores sobre Cidades Médias (RECIME) e ao Núcleo de Pesquisas Dinâmicas Urbanas e Patrimônio Cultural (NAUI-UFSC) desde 2004. Atualmente é professora colaboradora de Antropologia na Universidade do Estado de Santa Catarina, atuando na e com as disciplinas de Antropologia da Saúde e Sociologia. Tem interesse na área da antropologia urbana e antropologia da saúde, nas temáticas das corporalidades, saúde, práticas integrativas, dinâmicas urbanas e práticas corporais em espaços públicos.

Endereço profissional: Rua Sete de Setembro, n. 77D, Centro, Chapecó, SC. CEP: 89806-152.

E-mail: camila.sissa.antunes@gmail.com

ORCID: https://orcid.org/0000-0002-7570-7655

\section{Como referenciar este artigo:}

ANTUNES, Camila Sissa. Antropologia nos Cursos de Graduação na Área da Saúde: contribuições, relações e diálogos. Ilha - Revista de Antropologia, Florianópolis, v. 24, n. 1, e80698, p. 33-5l, janeiro de 2022. 